\section{Invasive marine animals get bigger}

For a wide group of marine pests, invasion is coupled with a marked increase in body size, a new study has found.

Edwin (Ted) Grosholz, UC Cooperative Extension specialist at UC Davis, and Gregory M. Ruiz of the Smithsonian Environmental Research Center in Edgewater, Md., compared the body sizes of 19 species of nonnative marine and estuarine invaders. These included crabs, shellfish and starfish, in their native habitats and other parts of the world where they have become invasive pests.

Twelve of the 19 showed increases in maximum size of up to $40 \%$. European green crabs and Chinese mitten crabs, both prominent nuisance species in U.S. waters, were about $20 \%$ bigger than in their native habitats. Only one, the gem clam, showed any sign of a decrease. The increases in body size were not clearly linked to differences in latitude between the native range and invaded areas or to the length of time since invasion.

The changes could be because the animals are no longer held back by predators or parasites, Grosholz says. "Animals and plants that are innocuous in their home environment can become rampaging pests when they invade a new area."

The results could have implications for understanding both how modern-day nuisance species become successful, and for interpreting fossil evidence of changes in populations of marine animals over millions of years.

The findings, published in the August 2003 Ecology Letters, appear to be unique to marine animals, as research in other taxa shows invading species both increasing and decreasing in size. "For example, the data for European plants invading California suggests that nearly $30 \%$ of invading species got smaller in the introduced range," Grosholz and Ruiz wrote.

\section{Food web changes documented in Lake Tahoe}

Dramatic food web changes have occurred as a result of the introduction of nonnative species into Lake Tahoe, according to a study by researchers at UC Davis and the University of Wisconsin, Madison.

The scientists documented important ecological changes in Lake Tahoe spanning the past 120 years. The researchers reconstructed the dietary niches of Lake Tahoe fishes dating back to 1872 by conducting stable isotope analysis of museum specimens and comparing them to fresh catches.

In particular, introduced lake trout (Salvelinus namaycush) and a freshwater shrimp (Mysis relicta) appear to have especially altered the food web, which may have implications for mounting efforts to restore populations of native Lahontan cutthroat trout (Oncorhynchus clarkii henshawi). Named for the distinctive red streak under its chin, this trout once topped the lake food chain at weights of 40 pounds. Due to overfishing, dam-building and habitat destruction, this species is now among the most endangered western salmonids and has been extinct in Lake Tahoe for 70 years. Some related but genetically distinct strains still live in lakes and streams outside of the Tahoe Basin.

At the 1997 Lake Tahoe Presidential Forum, then-President Bill Clinton and then-Interior Secretary Bruce Babbitt called for the Lahontan cutthroat trout to be restored to the Tahoe basin. For the past 2 years, the UC Davis/UW Madison research team has been collaborating with the U.S. Fish and Wildlife Service, assessing the current Lahontan cutthroat trout reintroduction efforts in Fallen Leaf Lake, a small lake located in the headwaters of Lake Tahoe.

"Fallen Leaf is turning out to be an ideal lake for Lahontan cutthroat trout reintroduction," says Jake Vander Zanden of UW Madison. "Plus, we're learning valuable lessons that will ultimately be transferred to other systems." The study was published in the April 2003 Ecosystems.

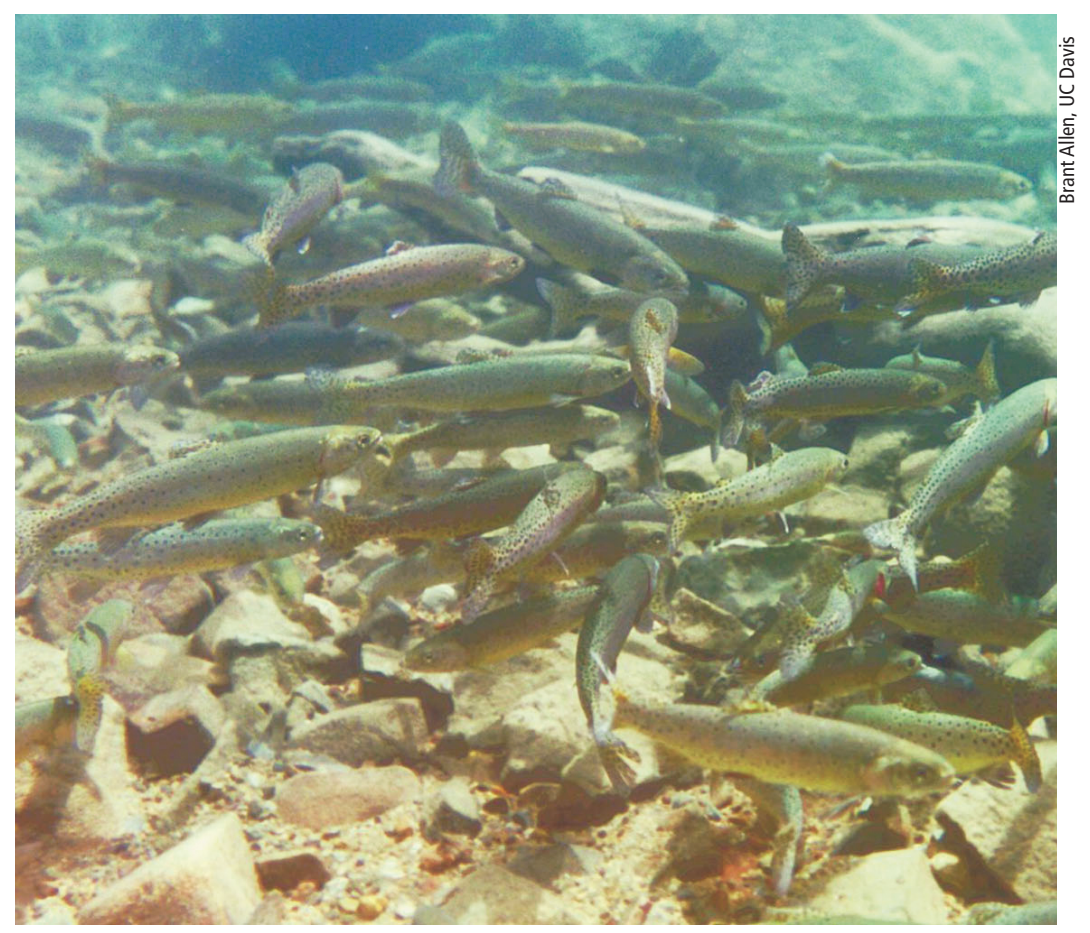

Once abundant in Lake Tahoe, Lahontan cutthroat trout are now extinct from the lake. These year-old fish were raised at the Lahontan National Fish Hatchery in Minden, Nev., and reintroduced into Fallen Leaf Lake. 